\title{
Ressignificando o ensino de doenças contagiosas com uma abordagem experimental em uma feira de ciências
}

\author{
Resignifying teaching about contagious diseases with an experimental \\ approach in a science fair \\ Geovane Rafael Theisen', Regiane Zanovello', Stéfani Dutra Mattana', \\ Terimar Ruoso Moresco 2, Tânea Maria Bisognin Garlet ${ }^{2}$ \\ ' Acadêmicos do curso de Ciências Biológicas UFSM - Palmeira das Missões. \\ ${ }^{2}$ Docente do Curso de Ciências Biológicas UFSM - Palmeira das Missões.
}

\begin{abstract}
Resumo
O presente trabalho apresenta considerações sobre uma atividade prática realizada em uma Feira de Ciências promovida por bolsistas do Programa Institucional de Bolsa de Iniciação à Docência PIBID/CAPES, no subprojeto de Ciências Biológicas da Universidade Federal de Santa Maria-Palmeira das Missões. A abordagem, de caráter experimental, ocorreu para demonstrar como ocorre uma epidemia a alunos da $6^{a}$ série [ $7^{\circ}$ ano] de uma escola da rede básica de ensino no município de Palmeira das Missões-RS. A apresentação dos resultados do experimento na Feira foi realizada pelos próprios estudantes onde o envolvimento e integração dos educandos na atividade foi decisivo para o bom desempenho do trabalho. O enfoque diferenciado dado ao ensino das doenças contagiosas serviu para aliar conceitos teóricos à prática e ressignificar às concepções de que ambientes não-formais de ensino, por exemplo, as feiras de ciências, também constituem um espaço socializador e significativo para a difusão dos temas relacionados à área de Ciências.
\end{abstract}

Palavras-chave: Feira de Ciências; Atividade experimental; Educação básica; Epidemia;

\begin{abstract}
This paper presents considerations about practical activity realized in a Science Fair organized by participants of the Programa Institucional de Bolsa de Iniciação à Docência PIBID/CAPES, in the subproject of Biological Science of the Universidade Federal de Santa Maria-Palmeira das Missões. The approach was to experimentally demonstrate an disease of contagious for 6th grade students [7th grade] of the a school from primary school in Palmeira das Missões-RS. The presentation of the results of the experiment at the Fair was held by the students where the involvement and integration of the students in the activity was crucial to the successful outcome of the work. The differentiated approach to teaching given disease of contagious served to combine theory with practice and reframe conceptions of environments that non-formal education such as the shows also provide a space for socializing and meaningful dissemination of topics related to the field of Sciences.
\end{abstract}

Keywords: Science Fair; Experimental activity; Basic education; Epidemic; 


\section{INTRODUÇÃO}

O ensino de ciências pode se processar em diferentes contextos educacionais e espaciais. Para cada contexto, diferentes definições e caracterizações são consideradas. Nesse enfoque, os espaços não formais ou ambientes extraescolares, inseridos na educação formal ou educação escolarizada também podem contribuir para o ensino de Ciências (FERNÁNDEZ, 2006).

A Feira de Ciências nessa concepção pode constituir um empreendimento técnico-científico-cultural para estabelecer o inter-relacionamento de saberes entre a escola e a comunidade. É definida segundo Ormastroni (1990) como uma exposição pública de trabalhos científicos e culturais realizados pelos alunos, que efetuam demonstrações, oferecem explicações orais, contestam as perguntas sobre os métodos utilizados e suas condições. No Brasil, as feiras surgiram e foram incentivadas a partir dos anos 60, como modo de aproximar a teoria da prática nas salas de aulas (MANCUSO \& MORAES, 2009 apud MEZZARI, 2011).

Bastante populares durante a década de 1990, as Feiras de Ciências estudantis têm uma tradição de mais de cinco décadas, e constituem uma oportunidade para estudantes apresentarem suas produções científicas escolares a um público diverso daquele que compõe o ambiente de suas salas de aula. Neste evento os alunos se responsabilizam pela divulgação de projetos planejados e executados por eles no decorrer do ano letivo, apresentam trabalhos desenvolvidos que resultaram em várias horas de estudo, investigação, busca por informações, interpretação e sistematização de dados. Desse modo, os alunos principiam nas atividades de iniciação científica, buscando soluções técnicas e metodológicas para os problemas que enfrentam no seu cotidiano.

Assim, o enfoque prático é uma das alternativas válidas entre os muitos modelos possíveis para materializar o ensino de ciências e atender as perspectivas de aprendizagem. Esse espaço, de abordagem prática e contextualizada, que as feiras oferecem, além de constituir uma ferramenta na problematização dos conteúdos, possui profunda significância no âmbito social.

Com isso, o trabalho objetivou promover a difusão de uma proposta experimental e demostrar como surgem as epidemias a estudantes da $6^{\mathrm{a}}$ série [ $7^{\circ}$ ano], para isso simulou-se a transmissão de uma doença contagiosa em uma proposta de atividade prática em uma Feira de Ciências.

\section{METODOLOGIA}

Buscando a efetivação de novas ferramentas metodológicas no ensino de Ciências, bolsistas do Programa Institucional de Bolsa de Iniciação à Docência /PIBID realizaram uma Feira de Ciências em uma escola da rede básica de ensino no município de Palmeira das Missões no mês de junho de 2013.

O tema central da Feira foi "Saúde e Ambiente", dando-se ênfase ao desenvolvimento de atividades práticas que fossem coerentes ao conteúdo trabalhado pelos professores em sala de aula. Assim, desenvolveu-se uma atividade com discentes da $6^{a}$ série [ $7^{\circ}$ ano] de uma escola da rede básica de ensino que demonstrasse a dinâmica da transmissão de uma epidemia, no caso trabalhado, a gripe.

Para a realização da atividade, utilizaram-se dez copos descartáveis. Neles, inicialmente os alunos separaram $120 \mathrm{ml}$ de água tônica deixando o gás sair completamente. Em seguida, distribuiu-se $60 \mathrm{ml}$ dessa água tônica em dois copos; esses seriam os copos "infectados". Logo após, para representar os copos "saudáveis" acrescentou-se água da torneira nos outros oito copos com o volume de $60 \mathrm{ml}$ cada. Na sequência, distribuíram-se os copos com água normal e os com água tônica aos alunos de maneira que os estudantes despejassem o conteúdo de seu copo no copo do colega vizinho dividindo igualmente os líquidos nos dois recipientes. Os discentes repetiram esse processo, porém deveriam tomar cuidado para não realizar o procedimento com o mesmo colega. Colocaram-se posteriormente, todos os copos dentro de uma caixa escura com luz negra, onde o contato com a água tônica tornaria os demais copos "infectados" o que resultaria na sua fluorescência.

No entanto, para que a atividade atingisse intrinsicamente seus objetivos, alguns aspectos importantes deveriam ser considerados: o fato de cada estudante poder trocar o conteúdo uma única vez com cada colega; os copos "infectados" deveriam ser entregues a alunos que estivessem em pontos opostos na sala de aula para evitar que ocorresse a troca entre dois copos com água tônica; e os alunos 
não poderiam ser comunicados de que havia copos com conteúdos diferentes, pois eles deveriam estar aparentemente idênticos.

\section{RESULTADOS E DISCUSSÃO}

Constituindo uma trajetória de quatro décadas, as Feiras de Ciências no Brasil demostram-se cada vez mais ativas e, nos dias atuais, esses eventos são organizados de modo a superar o conceito estagnado de fazer Ciência, redirecionando o ensino a um processo contextualizado e interdisciplinar.

Com isso, em 2005, a proposta de Feira de Ciências passou a ser melhor difundida com a criação do Programa Nacional de apoio às feiras de Ciências da educação Básica/FENACEB que possibilitou superar os desafios no ensino e estimular a realização de eventos com caráter de divulgação como é o caso de Mostras e Feiras desenvolvidas pelos alunos e professores. Diante da importância que a Ciência tem adquirido para o desenvolvimento da sociedade contemporânea, tornou-se fundamental a promoção de uma cultura científica que favoreça o processo de busca dos conhecimentos (BRASIL, 2006).

Partindo do pressuposto que o aprendizado só é efetivo quando decorre de uma postura investigativa, os conceitos e conteúdos curriculares de Ciência serão mais facilmente concretizados a partir do momento em que houver um vínculo entre teoria e a prática. Por esse motivo, Brasil (2006) sugere que as feiras podem ser importantes aliadas para promover essa interação, pois possui afinidade com a própria formação implicando no desenvolvimento gradativo do indivíduo. Além disso, esse tipo de evento é conhecido como uma atividade pedagógica e cultural com elevado potencial motivador do ensino e da prática científica no ambiente escolar. Tanto para professores quanto para a comunidade geral, as feiras vêm constituindo uma oportunidade de aprendizagem e de entendimento sobre as etapas de construção do conhecimento científico.

Nesse sentido, os trabalhos com atividades experimentais que geralmente são apresentados nas feiras atuam como ferramentas pelas quais os alunos podem se tornar ativos no processo de aprendizagem possuindo capacidade de sensibilizar e envolver a escola com os projetos de investigação. Além disso, eventos desse tipo podem também, segundo Silva \& Zanon (2000), exercer uma função pedagógica de forma a inter-relacionar saberes teóricos e práticos e assumir papel fundamental no processo de construção do conhecimento.

De acordo com Lemos (2007), a aprendizagem significativa baseia-se no estabelecimento de relações substantivas e não arbitrárias entre o conhecimento prévio do aluno e as novas informações a serem incorporadas na estrutura cognitiva dos indivíduos. Assim, esse tipo de aprendizagem passa a atribuir significados práticos aos conceitos teóricos, mas para isso a existência de conhecimentos prévios e a predisposição em aprender é fundamental (MOREIRA, 2008).

Na mesma perspectiva, Lowman (2004, p.233) considera que:

"As tarefas de observação e as experiências práticas podem enriquecer a interação dos estudantes com o conteúdo do curso regular e ajudá-los a ver a relevância do curso para as questões da vida real e das experiências humanas. Mas se os estudantes forem encorajados a tentar uma integração intelectual de suas experiências de fora da classe com o conteúdo do curso, tais tarefas também podem ajudá-los a analisar, sintetizar e a avaliar os conceitos aos quais foram apresentados."

Visto que, esse tipo de atividade baseada na experimentação pode, segundo Cruz (2008), ajudar no desenvolvimento mental dos alunos, na sua postura crítica, na aquisição de conhecimentos e aproxima o ensino de ciências do trabalho científico. Essas características à que Cruz (2008) se refere foram passíveis de serem observadas nos alunos enquanto realizavam a atividade. À medida que a abordagem experimental para demostrar a ocorrência da epidemia foi desenvolvida, o espírito cooperativo, socializador e cognitivo dos estudantes foi sendo despertado, possibilitando-os por conta própria compreender que a água tônica possui uma substância que, quando exposta à luz negra, emite fluorescência o que não seria possível de visualizar apenas com a propriedade da água da torneira.

$\mathrm{Na}$ mesma direção, Francisco et al. (2008) argumentam que a capacidade de explicar um fenômeno só é possível a partir do momento em que ele seja pessoalmente significativo e que instigue 
a curiosidade dos estudantes. Atividades diferenciadas são importantes no processo de aprendizagem, pois oferecem possibilidade de uma experiência de ensino não formal de Ciências, estabelecendo maior significância em relação à simples memorização da informação, método tradicionalmente empregado nas salas de aula (BAZIN, 1987). Assim, os discentes que antes eram acostumados a um ensino tradicional transmitido pela mera abordagem dos fatos, agora estão inseridos em um contexto atuante advindo do papel motivador da experimentação (Figura 1).

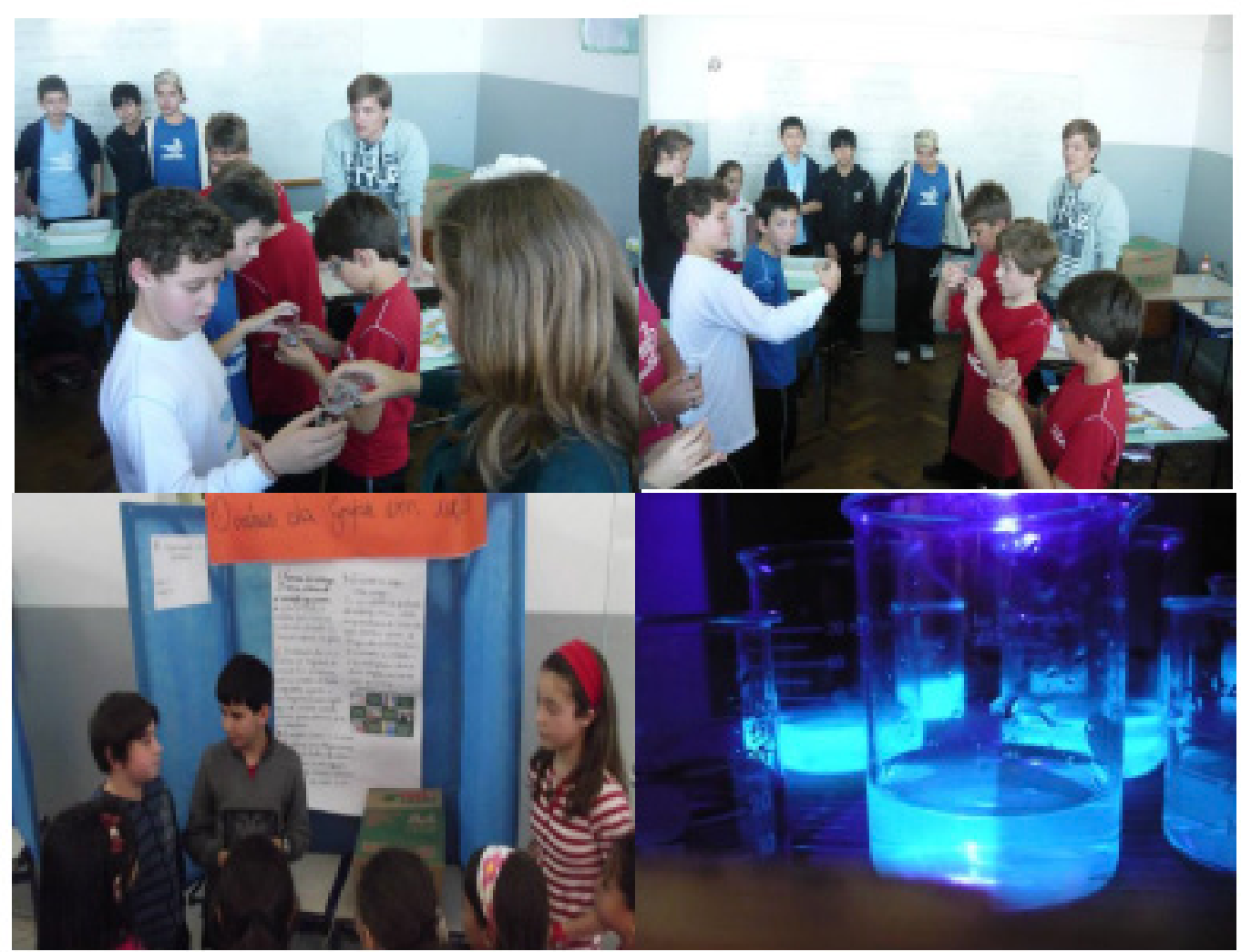

Figura 1- Estudantes da $6^{\mathrm{a}}$ série realizando a atividade experimental de demonstração de doença contagiosa e apresentando o resultado do trabalho na Feira de Ciências.

Além de a atividade prática favorecer o entendimento da dinâmica de transmissão de uma doença contagiosa, o trabalho desenvolvido na feira despertou a curiosidade e o interesse dos alunos, principalmente no momento em que eles participam ativamente das experiências tornando-a indissociável de sua vivência. Outra caraterística evidenciada na proposta experimental da feira foi a capacidade de interação dos conhecimentos com o cotidiano dos estudantes, e nesse aspecto o inter-relacionamento das informações entre os conteúdos é um ponto muito importante. Com isso, após a segunda etapa de trocas dos copos na atividade, $80 \%$ deles apresentaram-se fluorescentes. Essa "contaminação" entre os copos pode demonstrar a capacidade de propagação de uma doença contagiosa e nesse caso quanto maior for o número de alunos trocando o conteúdo em cada etapa, mais copos serão "contaminados" em menor tempo. Isso pode ser observado na atividade no momento em que os alunos realizaram e acompanharam o resultado do experimento à medida que buscavam soluções para o que estava acontecendo.

Embalado por esse desafio de experimentar, o aluno ainda desperta seu desenvolvimento intelectual, ao mesmo tempo em que se esforça para pensar e resolver problemas, na busca incessante por resultados. E, finalmente, o saber cotidiano passa a ser alvo de confronto. $\mathrm{O}$ aluno começa a ter novos posicionamentos diante dos experimentos e de seus resultados, adquirindo um saber mais científico (MEZZARI, 2011).

Dessa maneira, as atividades práticas constituem um fator essencial para o desenvolvimento cognitivo dos discentes. Carvalho et al. (2010) evidenciam que estas alternativas práticas proporcio- 
nam grandes espaços para que o aluno seja atuante, tornando-se agente do seu próprio aprendizado e descobrindo assim, que aprender é mais do que mero conhecimento de fatos.

Por conseguinte, a Feira de Ciências se estrutura como uma atividade cultural capaz de demostrar os resultados de um processo investigativo desenvolvido no campo científico. Ao encontro dessas colocações, Pereira (2012) destaca que as Feiras de Ciências representam uma excelente oportunidade para que o professor possa mediar a construção do conhecimento juntamente com seus alunos.

Para essas considerações Bizzo (2002, p.75) evidencia que:

(...) o experimento, por si só não garante a aprendizagem, pois não é suficiente para modificar a forma de pensar dos alunos, o que exige acompanhamento constante do professor, que deve pesquisar quais são as explicações apresentadas pelos alunos para os resultados encontrados e propor se necessário, uma nova situação de desafio.

Em consonância com as opiniões supramencionadas, Mancuso (2000) argumenta que as feiras trazem benefícios para alunos e professores e mudanças positivas no trabalho em ciências, tais como o crescimento pessoal e a ampliação dos conhecimentos; a ampliação da capacidade comunicativa; mudanças de hábitos e atitudes; o desenvolvimento da criticidade e maior envolvimento e interesse. Esse exercício da criatividade conduz à apresentação de inovações e a maior politização dos participantes.

\section{Além disso:}

[...] a realização de eventos deste tipo gera um movimento na comunidade escolar por colocar os alunos na condição de pesquisadores, o que pode causar uma tensão positiva que desperta nos alunos a necessidade de rever seus aprendizados anteriores e aprofundar conhecimentos, pois estão cientes que no momento da apresentação do trabalho para a comunidade muitos questionamentos irão surgir e os alunos apresentadores somente serão capazes de realizar a transposição didática se estiverem seguros do conhecimento que fundamenta sua ação enquanto mediadores no processo de ensino e aprendizagem. Desta forma, quanto maior a fundamentação teórica e o envolvimento nas atividades práticas que resultaram na produção do trabalho, melhor será a capacidade de interlocução do aluno no momento da socialização dos resultados do seu trabalho com a comunidade (MIRANDA NETO, et al., s.d., p.2).

Nesse mesmo contexto, Rosa (1995) apresenta algumas questões pertinentes a serem consideradas na organização das feiras. A adequação do trabalho ao currículo, a regularidade, a pesquisa, cotidiano e a relevância do tema à comunidade são pontos relativamente importantes que a autora sugere para que ocorra um adequado planejamento das atividades da Feira.

Por sua vez, um contraponto metodológico nesse processo, é que as feiras de ciências são utilizadas para repetição de experiências realizadas em sala de aula, montagem de exposição com fins demonstrativos, sem estímulo para aprofundar os estudos e busca de novos conhecimentos. Em trabalho realizado por Neuenfeldt et al. (2012) sobre interdisciplinaridade, criatividade e jogos/brincadeiras, evidencia-se que a centralização das atividades certamente faz com que se perca o compartilhamento de experiências. Com isso, para que situações dessas não ocorram é necessário ultrapassar as expectativas do ensino estagnado à reprodução de conceitos e partir para a busca de situações novas, fazendo e refazendo experiências que comtemplem também o imprevisto. É nessa proposta inovadora que o ensino de Ciências deve estar inserido, pois quando se propõem situações que não sejam a mera reprodução de fenômenos, mais facilmente desenvolvem-se habilidades cognitivas e investigativas advindas do processo de experimentação.

Esse tipo de atividade baseada na investigação pode aproximar o ensino de Ciências do trabalho científico, integrando, além da parte experimental, outros aspectos próprios das ciências, em que teoria e prática constituem algo que se complementam (MORAES, 2000). Esses pensamentos nos direcionam ainda, à ideia defendida por Lima et al. (1999), onde as atividade de caráter experimental inter-relacionam o aprendiz e os objetos de seu conhecimento, à teoria e à prática, ou seja, une a interpretação do sujeito aos fenômenos e processos naturais observados, pautados não apenas pelo conhecimento científico já estabelecido, mas pelos saberes e hipóteses levantadas pelos estudantes, 
diante de situações desafiadoras.

A partir dessa perspectiva de formação integral dos estudantes, as feiras se tornam espaços instrutivos, pois incentivam o desenvolvimento da capacidade comunicativa dos alunos transformando-se em ambientes que proporcionam proveitosas trocas de experiências. Visto que, após atuar numa feira, o aluno retornará à sala de aula com maior capacidade de decisão com relação aos problemas de seu cotidiano (BRASIL, 2006).

\section{CONCLUSÕES}

A Feira de Ciências promovida pelos bolsistas resgatou a valorização e o desenvolvimento de atividades científicas através da criação de um espaço para discussão, troca de experiências e disseminação de informações.

Uma vez que, cabe ainda destacar que quaisquer que sejam os assuntos abordados nos trabalhos de uma Feira de Ciências, todos eles, quando trabalhada de maneira integral e socializada, irão tornar o tema aplicável ao cotidiano dos estudantes tornando-se algo indissociável de sua vivência.

Logo, a utilização de ambientes extraescolares com a finalidade de desenvolver o aprendizado é um recurso eficaz na contemplação de inúmeras habilidades. No entanto, mediante suas potencialidades e significância ao ensino, é uma prática pouco explorada como estratégia de ensino-aprendizagem na educação formal.

Inter-relacionando, nossas considerações à concepção de que espaços não formais também constituem ambientes de aprendizado significativos, as ideias defendidas nesse manuscrito nos remetem ao entendimento de que esses eventos possibilitam a ampliação de novos horizontes à educação, por isso há a necessidade de ampararmos as feiras com uma orientação pedagógica que contribua para a difusão de um ensino de Ciências mais experimental, mais refletido e melhor fundamentado.

\section{AGRADECIMENTOS}

Os autores agradecem à Coordenação de Aperfeiçoamento de Pessoal de Nível Superior (CAPES) pela concessão de Bolsa no Programa Institucional de Bolsa de Iniciação à Docência/PIBID.

\section{REFERÊNCIAS}

BAZIN, M. Three years of living science in Rio de Janeiro: learning from experience.

Scientific Literacy Papers. 1987, p.67-74.

BIZZO, N. Ciências: fácil ou difícil. São Paulo: Ática. 2002.

BRASIL. Ministério da Educação. Programa Nacional de apoio às feiras de Ciências da educação Básica/ FENACEB. Brasília, 2006.

BRAUN, M.C.; DE SOUZA, N.G. E; GALEAZZI, C. Um "olhar" sobre as Feiras de Ciências. Coletânea Programa Pós-Graduação em Educação, v.4, p.27-33, 1997.

CARVALHO, U. L. R.; PEREIRA, D. D.; MACEDO, E.; SILVA, K.; CIBELI, M.; FOLENA, M. A importâncias das aulas práticas de biologia no ensino Médio. X Jornada de Ensino, Pesquisa e Extensão-JEPEX, UFRPE: Recife, out., 2010.

CRUZ, D.A. Atividades prático-experimentais: tendências e perspectivas. Secretaria de Estado da Educação Superintendência da Educação Programa de Desenvolvimento Educacional - PDE. Universidade Estadual de Londrina, 2008. 
FERNÁNDEZ, F. S. El aprendizaje fuera de la escuela - Tradición del pasado y desafio para el futuro. Madri: Ediciones Académicas. 2006.

FRANCISCO Jr, W. E.; FERREIRA, L. H., HARTWIG, D. R. Experimentação Problematizadora: Fundamentos Teóricos e Práticos para a Aplicação em Salas de Aula de Ciências. Química Nova na Escola, v.30, p.34-41, 2008.

LEMOS E.S. A teoria de aprendizagem significativa e sua relação com o ensino e com a pesquisa sobre o ensino. Aprendizagem Significativa em Revista/Meaningful Learning Review, v.3, p. 47-52, 2011.

LIMA, M.E.C.C.; JÚNIOR, O.G.A.; BRAGA, S.A.M. Aprender ciências - um mundo de materiais. Belo Horizonte: Ed. UFMG, 1999.

LOWMAN, J. Dominando as Técnicas de Ensino. São Paulo: Atlas. 2004.

MANCUSO, R. Feira de Ciências: produção estudantil, avaliação, consequências. Contexto Educativo. Revista Digital de Educación y Nuevas Tecnologías. Buenos Aires, v. 6, n. 1, p. 1-5, 2000.

MEZZARI, S.; FROTA, P. R. O.; MARTINS, M. C . Feiras multidisciplinares e o Ensino de ciências.

Revista Electrónica de Investigación y Docencia, número monográfico, p.107-119, 2011.

MIRANDA NETO, M. H., NETO, R. B., CRISOSTIMO, A. L. Desenvolver projetos e organizar eventos na escola. Disponível em: $<$ http://www.mudi.uem.br/index.php? option=com_content\&view= article\&id=330:d>. Acesso em 04 out. 2013.

MORAES, R. Construtivismo e Ensino de Ciências: reflexões epistemológicas e Metodológicas. Porto Alegre: EDIPUCRS, 2000.

MOREIRA, M.A. Subsídios metodológicos para o professor pesquisador em ensino de ciências: métodos qualitativos e quantitativos. Porto Alegre: Ed. do Autor, 2008.

NEUENFELDT, A.E.; RODRIGUES, A.W.L.; OLIVEIRA, W.F. Jogos Interdisciplinares: Uma possibilidade de Interação Criativa. Caderno pedagógico, Lajeado, v.9, n.1, p.79-97, 2012.

OSMATRONI, M. J. S. Manual de Feiras de Ciências. Brasília: CNPq, AED, 1990.

PEREIRA P. C. ; FONSECA, V.B.; MANZKE, V.H.B.; BROWSKI, V.L.; MANZKE, G.R. Feiras de ciências: uma ferramenta para aprendizagem significativa?.13 ${ }^{a}$ Mostra de Pesquisa, Ensino e Extensão, Instituto Federal de Educação, Ciência e Tecnologia do Rio Grande do Sul Campus. Porto Alegre, 2012.

ROSA, P.R.S. Algumas questões relativas a feiras de ciências: para que servem e como devem ser organizadas. Caderno Catarinense de Ensino de Física, v.12, n.3, p. 223-228, 1995.

SILVA, L. H. de A. \& ZANON, L. B. Ensino de Ciências: fundamentos e abordagens. São Paulo: UNIMEP, 2000. 